\title{
Responsabilidade Social Corporativa e Educação para a Carreira: Um Estudo de Caso Internacional
}

\section{Corporate Social Responsibility and Career Education: An International Case \\ Study}

\author{
Cristina Costa-Lobo*, Filomena Ponte**, Ana Rita Martins*, Maria das Dores Formosinho*, Ana Campina* \\ *Universidade Portucalense Infante D Henrique; **Universidade Católica Portuguesa
}

\begin{abstract}
Resumo
O presente estudo pretende contribuir para a compreensão dos processos de responsabilidade social corporativa em contexto de educação para a carreira. Descrevem-se as etapas, sinalizam-se os resultados centrais e discutem-se as implicaçoes de um estudo realizado numa empresa portuguesa, com atuação em contextos internacionais, empresa de distribuição alimentar, no sentido de perceber a sua visão e atuação de responsabilidade social assim como a relação desta com a educação para a carreira dos seus colaboradores.
\end{abstract}

Palavras-chave: Educação para a carreira, responsabilidade social corporativa, estudo de caso

\begin{abstract}
This study aims to contribute to the understanding of the processes of corporate social responsibility in the context of career education. The stages are described, the central results are indicated and the implications of a study carried out in a Portuguese company, working in international contexts, a food distribution company, in order to perceive its vision and performance of social responsibility are discussed. Such as its relationship with education for the career of its employees.

Keywords: Career education, corporate social responsibility, case study
\end{abstract}

\section{Introdução}

A Responsabilidade Social Corporativa (RSC) e a educação para a carreira emergem num contexto de uma sociedade evoluída, globalizada, tecnológica e em constante mutação. Essas evoluções e transformações afetam diretamente as exigências económicas no sentido em que "numa economia tão instável e dinâmica, a principal fonte de vantagem competitiva são as próprias pessoas, em particular a habilidade que possuem para antecipar mudanças, adaptar-se a novas circunstâncias e inventar novas práticas de negócio" (Neto \& Alves, 2012, p.197), assim como as do mundo do trabalho, cada vez mais marcado pela competitividade, "mercados que se alteram rapidamente, evolução tecnológica ininterrupta e inovações organizacionais" (Neto \& Alves, 2012, p.197). Assim, "a revolução do conhecimento trouxe às organizações e às pessoas novas formas de construir os seus percursos e as suas identidades profissionais e vocacionais" (Costa-Lobo, \& Ferreira, 2012, p.201). Surge então a educação para a carreira como resposta eficaz às novas exigências dos contextos profissionais como a adaptabilidade, flexibilidade, formação continua e polivalência.

A RSC pode ser entendida como conjunto de acções voluntárias levadas a cabo pelas organizações no sentido da criação de oportunidades que salvaguardem e desenvolvam as sociedades em que estão inseridas. "Isto significa que concordar com a responsabilidade social das organizações implica o desenvolvimento de acções com interesse para a sociedade mesmo que não contribuam directamente para o lucro da empresa" (Teixeira, 2013, p.369). Segundo o mesmo autor, as principais áreas constituintes da atuação da RSC são os consumidores, os empregados, o ambiente e a sociedade em geral. Quanto aos consumidores "as questões levantadas nesta área dizem respeito, acima de tudo, à segurança dos produtos que as empresas colocam no mercado, design e preços justos" (p.371). No que diz respeito aos empregados "questões como a segurança no trabalho, o pagamento do justo salário, a indiscriminação com base no sexo, raça ou religião o treino, educação e desenvolvimento dos trabalhadores, a assistência a empregados com problemas, estão na ordem do dia (p.373). Em relação ao ambiente evidenciam-se "as preocupações de higiene, a par da segurança, nomeadamente nos locais de trabalho, mas não só, a protecção contra a poluição, o maior recurso a embalagens biodegradáveis e recicláveis, o tratamento de produtos perigosos para a sociedade, como o lixo nuclear (p.373). Assim, a RSC impõe uma série de objetivos sociais às organizações "os quais devem englobar o controlo da poluição, melhoria das condições de trabalho, política de emprego de minorias, desenvolvimento da comunidade, contribuições filantrópicas e aspectos relacionados com o consumidor (p.375). Por sua vez, a educação para a carreira pode ser entendida como uma modalidade de intervenção sistemática que abrange todos os momentos da vida do individuo e pretende dotá-los de competências para que 
possam tomar autonomamente decisões adequadas relativamente ao processo de construção de carreira. Neste contexto de RSC e de gestão de carreiras evidencia-se a necessidade de abordar a educação de adultos e a aprendizagem ao longo da vida que têm vindo a ser estudadas desde a década de 60 apesar das evidentes alterações nos termos e conceitos que as constituem.

De acordo com Costa-Lobo e Ferreira (2012) "a revolução do conhecimento trouxe às organizações e às pessoas novas formas de construir os seus percursos e as suas identidades profissionais e vocacionais" (p.201), isto é, as transformações sociais, politicas e económicas resultantes da globalização trouxeram novas exigências ao mundo profissional influenciando assim as decisões a tomar no decorrer da construção de carreiras. A teoria socio cognitiva no domínio da carreira "focaliza a capacidade auto-regulatória de aprender e de desenvolver as estratégias adaptativas para lidar com as contingências pessoais e situacionais" (Costa-Lobo \& Ferreira,2012, p.202). O modelo sócio-cognitivo de escolhas vocacionais, analisando o processo de seleção de carreira como um processo de desdobramento, remete-nos para a importância da sinalização de influências múltiplas e múltiplos pontos de escolha. Segundo esta teoria, quando os indivíduos experienciam fracas barreiras e um apoio ambiental forte, maior é a probabilidade de os seus interesses de carreira se transformarem em objetivos e estes por sua vez se transformarem em ações. Por outras palavras "as variáveis suportes e barreiras contextuais podem moderar o processo de transformação de objetivos, isto é, as relações entre interesses e objetivos e as relações entre objetivos e ações são esperadas mais fortes aquando da presença de condições ambientais favoráveis" (Costa-Lobo \& Ferreira,2012, p.204). Os processos de tomada de decisão são explicados através de teorias e modelos de decisão que se dividem em três abordagens. A primeira abordagem considera a decisão vocacional como um processo desenvolvimental que passa por várias fases, e por sua vez, esse conjunto de decisões decorrentes ao longo da vida, constituem a construção da carreira. A segunda abordagem concentra-se essencialmente na forma como os indivíduos fazem as escolhas a nível vocacional dividindo-se em modelos prescritivos e descritivos de tomada de decisão. Os modelos prescritivos analisam as decisões enquanto que os descritivos procuram analisar os processos de tomada dessas decisões. A terceira abordagem evidencia as variáveis individuais dos decisores como são exemplo os traços de personalidade, estilos de decisão, as dificuldades no processo de tomada de decisão e a indecisão vocacional.

Quanto à implementação da escolha como fase do processo de decisão destacam-se modelos desenvolvimentistas, cognitivos e sócio-cognitivos. Nos modelos desenvolvimentistas, a decisão vocacional é considerada parte integrante de um processo dinâmico de desenvolvimento vocacional e "é iniciada pela experiência de um problema vocacional e pelo reconhecimento da necessidade de tomar uma decisão" (Carvalho, M., \& Taveira, M., 2012, p.2). Nesta perspetiva, a decisão vocacional desenvolve-se em ciclos de planeamento e de execução, ou seja, inicialmente o individuo antecipa e explora alternativas e soluções para o problema vocacional, e posteriormente aplica essas soluções e ajusta-se ao novo contexto.

\section{Estudo Empírico}

Este ponto do trabalho constitui-se pela apresentação da metodologia do estudo realizado no grupo empresarial em estudo. Procede-se assim à apresentação dos objetivos do estudo, da metodologia utilizada, à descrição dos instrumentos de recolha de dados, e à caracterização da amostra e do contexto. Este estudo pretende obter informações sobre o grupo empresarial escolhido no que respeita à perspetiva e concretização da RSC assim como acerca da sua formação. Assim, pretende-se perceber o contexto e a forma de atuação do fundo de emergência social, obter informações acerca dos pilares, princípios e valores do grupo na sua atuação socialmente responsável, compreender objetivos e formas de ação do fundo de emergência social, e por último perceber o papel das assistentes sociais no fundo de emergência social.

Esta investigação concretizou-se com um estudo de caso, com recurso à análise documental e a entrevistas e análise de conteúdo com rentabilização do método de Bardin. Cumpriram-se as etapas pré-analítica, exploratória e de tratamento e interpretação qualitativa de respostas. A fase pré-analítica implicou a observação das regras de exaustividade (seleção de todo o material suscetível de utilização), representatividade (os dados foram obtidos por intermédio de técnica idêntica e realizada com indivíduos semelhantes), homogeneidade (os documentos retidos obedeceram a critérios precisos de escolha) e pertinência (os documentos retidos foram adequados ao objetivo da análise). Após a organização dos materiais e sistematização das ideias iniciais, foi realizada uma leitura sistemática das respostas. Na fase de exploração do material, os dados brutos foram transformados visando alcançar o núcleo de compreensão do texto. Realizou-se a classificação e a agregação do material das respostas de forma a atingir uma representação do seu conteúdo. $\mathrm{Na}$ última fase de tratamento e interpretação qualitativas foram analisadas todas as respostas e tomadas todas as unidades de análise que possibilitaram a posterior categorização. Como regra de enumeração, foi utilizada a frequência, representada pelo número de vezes que determinada categoria apareceu referenciada na resposta ao item em análise. Da sistematização das categorias de análise surgiram os seus respetivos temas ou núcleos de sentido, encontrados a partir da revisão da literatura que norteou e precedeu a recolha dos dados.

No sentido de garantir alguma liberdade e adaptabilidade nas questões e nas respostas optou-se pela elaboração de entrevistas semiestruturadas. No sentido de obter informações sobre a perspetiva e concretização da RSC e da formação no grupo empresarial alvo do estudo, recorreu-se ao Inquérito sobre Responsabilidade Social Corporativa e Educação para a carreira (IRSCEC) realizado via Skype à diretora da área de desenvolvimento do grupo em questão. O IRSCEC teve a duração de aproximadamente 60 minutos e constitui-se 
por 17 questões de formato aberto que se dividem essencialmente em duas partes, sendo as primeiras seis relacionadas com a RSC e as ultimas 11 relacionadas com a Educação para a carreira.

Para melhor perceber o contexto e forma de atuação do fundo de emergência social realizou-se o Inquérito sobre o Fundo de Emergência Social ao coordenador do fundo de emergência social. A sua implementação foi presencial, durou aproximadamente 60 minutos, e teve como objetivo a obtenção de informação acerca dos pilares, princípios e valores do grupo na sua atuação socialmente responsável assim como compreender os objetivos e formas de ação do fundo de emergência social. Constitui-se por 19 questões de formato aberto que se dividem essencialmente em duas partes, sendo as primeiras nove relacionadas com a responsabilidade social corporativa e as ultimas 10 sobre o fundo de emergência social.

De forma a perceber o papel e estatuto das assistentes sociais no fundo de emergência social recorreu-se ao Inquérito às Assistentes Sociais no Fundo de Emergência Social. Este inquérito por entrevista foi realizado presencialmente, com a duração de aproximadamente 30 minutos, a três das assistentes sociais do fundo de emergência social do grupo empresarial em estudo e teve como principal objetivo compreender qual o contributo dos trabalhadores sociais neste âmbito assim como perceber qual o estatuto que detêm. Constitui-se por cinco questões de formato aberto.

A amostra desta investigação trata-se de uma amostra de conveniência e constitui-se por cinco elementos. Assim, é composta pela directora da área de desenvolvimento, pelo coordenador e por três assistentes sociais do fundo de emergência social da empresa em estudo. A sua colaboração passou pela disponibilização de informações em forma de entrevista onde foram explorados os dois principais eixos deste estudo: a RSC e a educação para a carreira. De forma a melhor contextualizar o caso em estudo, apresenta-se de seguida uma breve descrição sobre o grupo empresarial alvo deste estudo. Este grupo atua no ramo alimentar, nos sectores da Distribuição, da Indústria e dos Serviços e possui mais de 3500 lojas distribuídas em Portugal e nos outros dois países onde atua. No respeitante à estratégia empresarial, o grupo vê na contratação de profissionais a hipótese de proporcionar respostas rápidas e eficazes aos desafios que enfrenta, esperando destes o envolvimento e a paixão pelo negócio, sentido de responsabilidade e compromisso, vontade permanente de aprender, identificação com a cultura do grupo, espírito de equipa a resiliência. De forma a garantir que cada colaborador faz o seu melhor, o grupo investe na sua formação e desenvolvimento pois considera que só assim obterá uma vantagem competitiva sustentável. $\mathrm{O}$ grupo entende que este investimento deve ser prioritário e a tempo inteiro e para que seja eficaz implica o reconhecimento das necessidades dos colaboradores assim como o seu enquadramento na evolução do negócio.

\section{Apresentação, análise e discussão dos resultados}

Neste ponto do trabalho apresentam-se os resultados obtidos neste estudo assim como a sua análise e discussão. Para esta empresa, a gestão de carreiras dos colaboradores é muito valorizada sendo que é transversal a todos, desde os cargos mais relacionados com as operações até aos cargos de chefia. A formação é vista como um poderoso instrumento para o desenvolvimento pessoal e profissional destas pessoas. Assim, este grupo empresarial investe muito na sua formação tanto na fase de acolhimento e integração na empresa, como na fase intermédia da carreira que poderá ser de transição ou enriquecimento da função.

A sinalização e o diagnóstico de necessidades de formação são traçados de forma estratégica, isto é, são definidos em função dos objetivos anuais da empresa e da estratégia de negócio. A formação de acolhimento pretende que os colaboradores, quando integram a empresa, estejam preparados e sejam detentores dos conhecimentos necessários para executar determinada função. Por sua vez, a formação de transição e/ou enriquecimento da função destina-se a colaboradores que vão transitar de função ou a colaboradores que já estão há algum tempo em determinada função é precisam de algum enriquecimento ou refreshment. Neste âmbito desenvolvem-se por exemplo programas de formação para gerentes de loja e chefes de secção e parcerias com universidades. Além das formações de acolhimento e transição ou enriquecimento da função, também são desenvolvidas outras relacionadas com a responsabilidade social: uma direcionada para colaboradores que se prende com a gestão economia doméstica, e outra direcionada para embaixadores do fundo de emergência social. Desta forma pode perceber-se que na visão deste grupo empresarial, a formação dos seus colaboradores não se trata de uma medida de responsabilidade social. Este grupo entende que a formação é uma medida que irá contribuir fortemente para o melhor e mais eficaz desempenhar de funções dos colaboradores e que deverá ser definida de acordo com os objetivos e estratégias do negócio. A responsabilidade social, por sua vez, implica todas as medidas que não contribuem diretamente para desempenho profissional do colaborador, mas que o ajudam e contribuem para o seu bem-estar. Desta forma, esta área não é orientada para objetivos de negócio, mas sim para a ajuda e o apoio dos seus membros do grupo.

Em termos de responsabilidade social o grupo definiu três pilares de acordo com as necessidades evidenciadas pelos seus colaboradores, que norteiam a sua intervenção, sendo estes a educação, a saúde e o bem-estar familiar. No âmbito da educação existe uma medida transversal e medidas destinadas a grupos mais específicos. A atribuição do vale de regresso as aulas é o exemplo da medida transversal do pilar educação porque é dirigida a todos os colaboradores. Por sua vez, a atribuição do kit escolar destina-se apenas a colaboradores com filhos que iniciam o primeiro ano escolar. As medidas relacionadas com bolsas de estudo, integração no sistema escolar e manuais escolares destinam-se essencialmente a colaboradores integrados em famílias que apresentam problemas financeiros e por isso a sua atribuição/implementação depende de uma avaliação e de uma resposta a determinados critérios. No âmbito da saúde, e mais uma vez de acordo com as 
necessidades evidenciadas pelos colaboradores, desenvolvem-se apoios que permitem o acesso a cuidados de saúde especializados por parte dos colaboradores e em alguns casos também das suas famílias. Os programas de apoio em doenças oncológicas destinam-se não só ao colaborador, mas também à sua família. O apoio em consultas de dentista é uma das medidas que inicialmente se destinava aos colaboradores e que mais tarde passou a abranger também os seus filhos. Existem também protocolos com entidades de saúde que permitem o acesso a consultas de especialidade por um preço mais acessível. Em relação às doenças raras os apoios também abrangem toda a família e passam por exemplo pelo pagamento de um cuidador para uma situação pontual. Por ultimo, e a acontecer apenas pontualmente, temos o pagamento de medicamentos que se destina a casos muito específicos de famílias com dificuldades financeiras para assegurar a compra regular de um determinado medicamento ou de determinada alimentação. No âmbito do bem-estar familiar, podem-se identificar cinco principais medidas nomeadamente o apoio em cartão de alimentação, o apoio jurídico, o apoio financeiro, o kit de bebé e a articulação com a segurança social. $O$ cartão de alimentação, limitado a bens essenciais, é a medida onde o grupo tem o maior investimento. Por vezes, esta medida é acionada para que o colaborador possa canalizar a verba que estaria destinada à alimentação, para a resolução de um determinado problema como por exemplo o pagamento de uma divida. $\mathrm{O}$ apoio jurídico passa essencialmente por casos de divórcio com outros problemas associados, pela regulação do poder paternal e pela resolução de problemas relacionados com dividas, através da atribuição de um advogado ou da disponibilização de consultoria financeira. Por sua vez, o apoio financeiro trata-se de questões pontuais que poderão passar pelo pagamento de um título mensal de transporte, pagamento da parte não subsidiada pela segurança social de um funeral ou até adiantamento do subsidio de natal e/ou férias. O kit de bebé também é uma medida da dimensão do bem-estar familiar e destina-se a todos os colaboradores que têm filhos recém-nascidos.

$\mathrm{O}$ fundo de emergência social articula com a segurança social por exemplo com questões relacionadas com o pagamento de pensões. Os problemas apresentados pelos colaboradores por vezes são de uma determinada área, mas as soluções encontradas para os colmatar são referentes a outras áreas, isto é, poderão ser resolvidas questões financeiras com apoio jurídico ou poderão ser resolvidas questões jurídicas com apoios financeiros. Em relação à sua atuação no âmbito da responsabilidade social interna pode-se concluir que vários são os esforços para ir de encontro às necessidades que os seus colaboradores evidenciam. Sendo assim, foram elaborados inquéritos de diagnóstico e de reavaliação de necessidades, em 2008 e 2014, onde foram definidos e revistos os três pilares de atuação, foram levantadas novas necessidades e foram adaptados processos e medidas de apoio.

\section{Conclusão}

Para a empresa em estudo a responsabilidade social pressupõe a satisfação de necessidades e proteção dos seus membros evidenciando assim a sua preocupação em termos de desenvolvimento humano. São também evidentes as medidas no âmbito da cidadania empresarial assim como uma forte cultura organizacional apreendida no decorrer do tempo. Nesta entidade a cidadania, a sustentabilidade, a gestão dos stakeholders e a ética são patentes nas práticas de responsabilidade social. Nesta empresa a responsabilidade social não se confunde com marketing social sendo efetivamente uma estratégia diferenciadora e de reforço da sua imagem.

Com a análise dos inquéritos por entrevista, instrumento utilizado para a recolha de dados, pode concluir-se que o modelo Value, Balance, Accountability está assegurado. É evidente a preocupação e existência do equilíbrio entre a geração de valor e o balanço entre os valores humanos e a função da empresa bem como a existência de uma relação socialmente responsável com a sociedade. Em particular os resultados obtidos através do Inquérito sobre Responsabilidade Social Corporativa e Educação para a carreira permitiram a sinalização do enfoque que esta empresa atribui à adaptação às transformações sociais.

Neste estudo há também evidências da valorização da formação como uma efetiva oportunidade de aprendizagem que é organizada, estruturada, situada no tempo, previamente construída e com objetivos específicos onde o formando assume o papel de recetor de informação e conhecimentos.

O trabalho colaborativo foi particularmente evidenciado no âmbito do Inquérito sobre o Fundo de Emergência Social e do Inquérito às Assistentes Sociais no Fundo de Emergência Social tendo sido possível aferir a concretização de iniciativas promotoras de efetiva colaboração entre os diferentes agentes, ainda que sem estatuto laborar de liderança. Em particular o trabalho colaborativo é valorizado e estimulado na figura do embaixador e do assistente social. Estes colaboradores assumem um conjunto plural de tarefas que contribuem para um determinado fim comum, mas que não têm em consideração os objetivos individuais. Tal como o estudo realizado por Baptista (2010) os resultados desta investigação apontam no sentido da pertinência da colaboração que "pressupõe uma tomada de decisão conjunta, a partilha de informação, a comunicação, onde os vários participantes, sem relação hierárquica, trabalham em conjunto para atingirem os mesmos objetivos" (p.66). e que tem como vantagens "enriquecer o trabalho profissional; reforçar a eficiência; promover a coordenação e partilha de responsabilidade; fortalecer a auto-eficácia e confiança; desenvolver a capacidade de reflexão" (Baptista, M., 2010, p.66). O trabalho colaborativo pressupõe e promove a interação, comunicação, diálogo, envolvimento, tomadas de decisão conjuntas, resolução de problemas e distribuição de papeis e/ou tarefas.

Com a realização dos inquéritos por entrevista foi possível dar resposta à totalidade dos objetivos elencados. Obtiveram-se informações acerca da 
perspetiva e formas de atuação deste grupo empresarial no que respeita à RSC percebendo a sua formação e a sua gestão de carreiras. Quanto ao fundo de emergência social pudemos ficar a perceber a sua história, o seu contexto, a sua forma de atuação e os seus agentes através da compreensão dos seus princípios, valores e pilares de atitude socialmente responsável.

Em suma, este estudo permite evidenciar que o desenvolvimento profissional é um processo complexo orientado para a mudança de conceções e para o desenvolvimento pessoal e social, resulta do reconhecimento da necessidade do profissional aprofundar e adquirir conhecimentos ao longo da carreira, recorrendo a instrumentos como a formação, a reflexão e o trabalho colaborativo.

\section{Referências}

Bandura, A (1991) Social cognitive theory of self-regulation. Organizational Behavior and Human Decision Processes, 50, 248-287.

Campos, B.P. (2001) A orientação vocacional numa perspetiva de intervenção no desenvolvimento psicológico. Revista Portuguesa de Pedagogia, XIV, $185-230$

Carroll, A., (1991) The pyramid of corporate social responsibility: toward the moral management of organizational stakeholders. Business Horizons, July- august, 39-48.

Carvalho, M., \& Taveira, M. (2012) A implementação de decisões vocacionais: Revisão da literatura.

Costa-Lobo, C. \& Ferreira, A. T. (2012). Educação para a carreira: Contributos para a Tomada de Decisão nas Transições Profissionais. In: Alves, J. S. \& Neto, A. M. S. (org.), Decisão: Percursos e Contextos (pp. 201206). Vila Nova de Gaia: Eu Edito.

Ferreira, H., Gonçalves, C., \& Coimbra, J. (2008, Outubro). O impacto do contexto de trabalho na auto-eficácia profissional. Comunicação apresentada no X congresso internacional de formação para o trabalho, Chaves, Portugal.

Garcia, A. (1999) Responsabilidade social não é ajuda, é respeito. Gazeta Mercantil.

Gomes, L. (2014) Exploração e indecisão vocacional em alunos do ensino superior: estudo exploratório. Dissertação de mestrado, Universidade Portucalense Infante D. Henrique.

Guedes, R. (2014) Responsabilidade social \& cidadania empresariais: Conceitos estratégicos para as empresas face à globalização.

Jerónimo Martins. (2015). Relatório de Responsabilidade Corporativa 2015. Disponível em http://www.jeronimomartins.pt/responsabilidade/relat orios- responsabilidade.aspx

Michel, M.O., Lampert, M.A. (s/data) Responsabilidade social ou marketing para causas sociais.

Morgado, J. (2013). O estudo de caso na investigação em educação. Santo Tirso: De Facto Editores

Quivy, R., \& Campenhoudt, L. (1998). Manual de investigação em ciências sociais. Lisboa: Gradiva
Rebelo, T. (2006) Orientação cultural para a aprendizagem nas organizações: condicionantes e consequentes. Tese de doutoramento não publicada, Faculdade de Psicologia e de Ciências da Educaçãoda Universidade de Coimbra.

Rego, A., Cunha, M., Costa, N., Gonçalves, H., \& Cabral-Cardoso, C. (2006). Gestão ética e socialmente responsável: teoria e prática. Lisboa: Editora RH.

Schwartz, M., \& Carroll, A. (2008). Integrating and unifying competing and complementary frameworks: the search for a common core in the business and society field. Business \& Society 47, 148-186.

Teixeira, S. (2013). Gestão das Organizações. Lisboa: Escolar Editora.

Zenone, L. (2006). Marketing Social. São Paulo: Thomson Learning. 